\title{
SCREENING FOR CUSHING'S SYNDROME IN OBESE
}

\section{PATIENTS}

Alhambra Expósito, MR; Tenorio Jiménez, C; Prior Sánchez, I; Molina Puerta, MJ; Moreno Moreno, P; Muñoz Jiménez, C; Gálvez Moreno, MA; Benito López, P.

Servicio de Endocrinología y Nutrición. Hospital Universitario Reina Sofía. Córdoba. Spain.

\section{INTRODUCTION}

Cushing's syndrome (CS) is considered to be more frequent among patients with metabolic syndrome. Previous studies have suggested to perform a routine screening for CS in obese patients; however, more recent reports only recommend a case-finding approach in patients with uncontrolled diabetes and hypertension, despite appropriate treatment.

\section{OBJECTIVE}

The aim of this study was to evaluate the prevalence of unsuspected CS in morbidly obese patients in an outpatient's clinic.

\section{PATIENTS AND METHODS}

We reviewed the medical records of morbidly obese patients referred to our clinic prior to bariatric surgery between January 2001 and December 2011. All patients had a complete medical history including physical examination, and 387 (300 female; mean age $46,5 \pm 11,2 \mathrm{yr}$; mean BMI 52,8 $\pm 27,1 \mathrm{~kg} / \mathrm{m}^{2}$ ) underwent screening for $\mathrm{CS}$ as part or our pre-surgical protocol. As screening for autonomous cortisol secretion, we performed an overnight $1 \mathrm{mg}$ Dexamethasone Suppression Test (DST). Serum cortisol $<1,8$ $\mu \mathrm{g} / \mathrm{dl}$ was the cut-off point for normal suppression.

\section{RESULTS}

387 patients ( $77 \%$ female) $46.63 \pm 11.06$ years old BMl: $52.73 \pm 26.01 \mathrm{~kg} / \mathrm{m}^{2}$

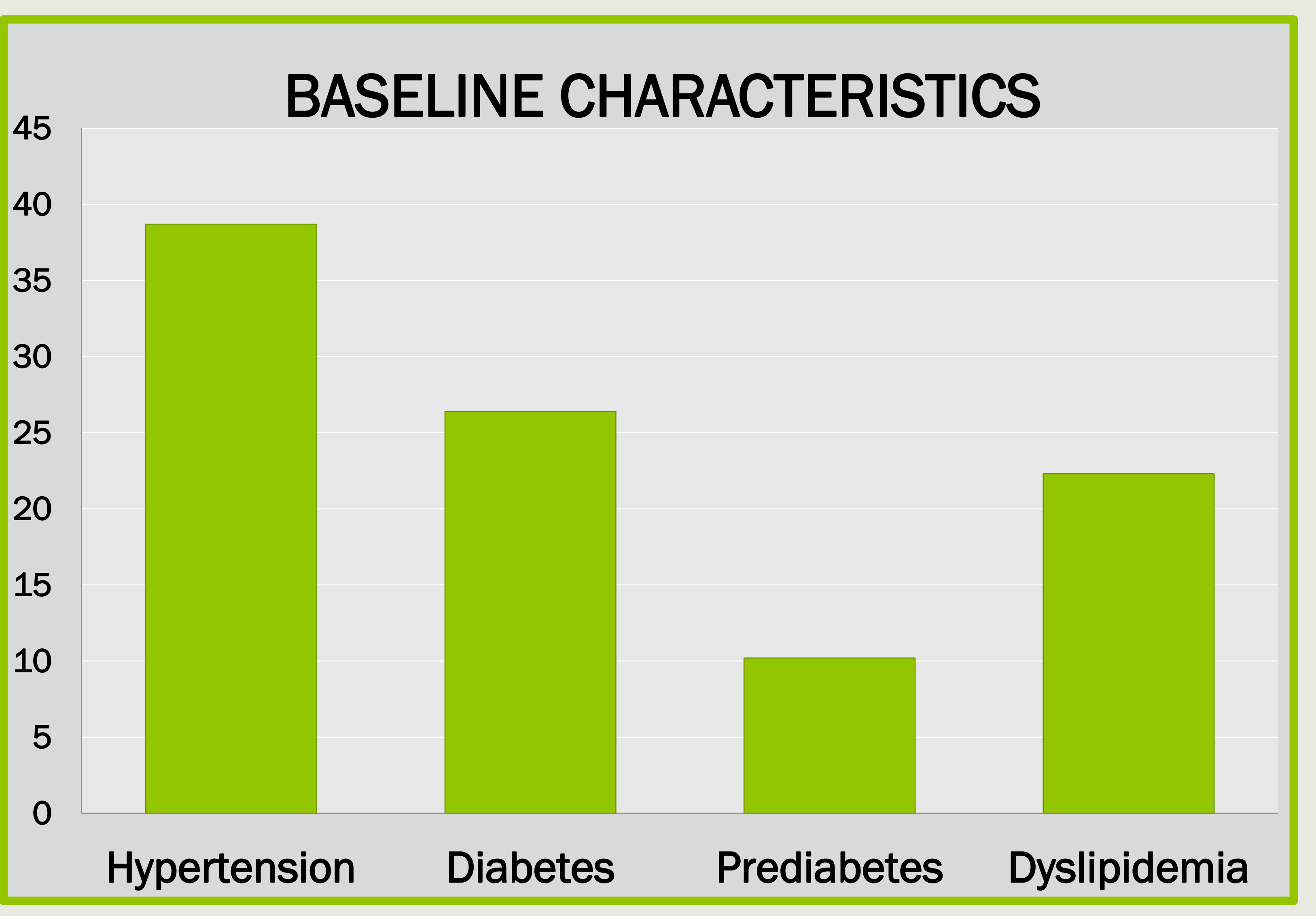

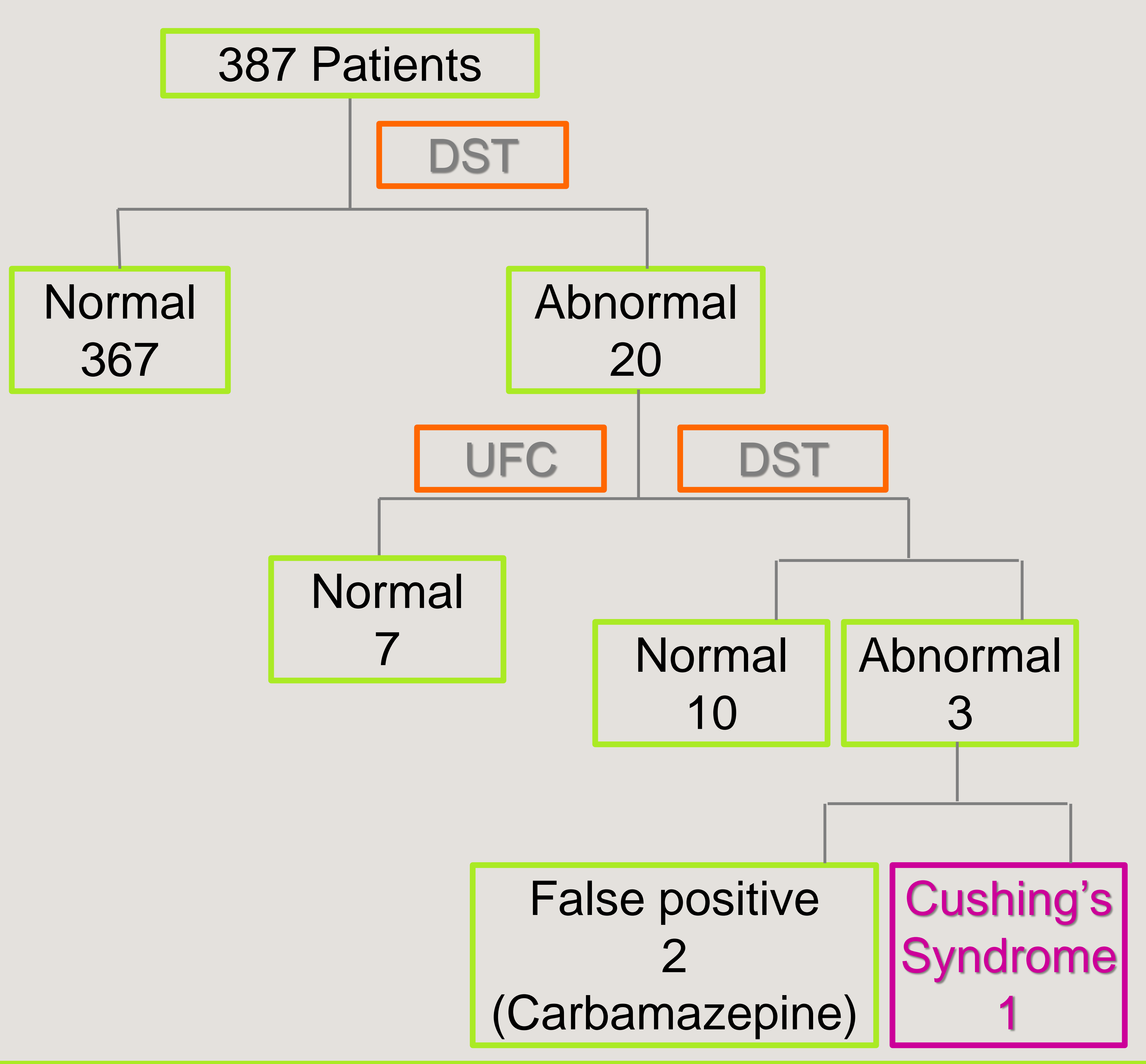

\section{CONCLUSIONS}

A low proportion of patients with morbid obesity were found to have CS. Our findings suggest that morbidly obese patients should not be routinely screened for CS. 